\title{
VASCULITE LIVEDOIDE: RELATO DE CASO
}

\author{
LIVEDOID VASCULITIS: CASE REPORT \\ Rafaela Sorpile Araujo ${ }^{1 *}$, Odirlei Antonio Magnagnagno ${ }^{2}$, Orley Alvaro Campagnolo ${ }^{3}$ \\ ${ }^{1}$ Acadêmico do curso de Medicina do Centro Universitário Assis Gurgacz, ${ }^{2}$ Docente do curso de \\ Medicina do Centro Universitário Assis Gurgacz, ${ }^{3}$ Médico Dermatologista Docente do curso de \\ Medicina do Centro Universitário Assis Gurgacz
}

*Autor Correspondente: rafaelasorpile@gmail.com, https://orcid.org/0000-0002-2977-0688

\begin{abstract}
RESUMO
Relata-se o caso de vasculite livedoide em paciente feminina de 41 anos com úlceras dolorosas em membros inferiores com desfecho favorável. Estudo histológico evidenciou espessamento de feixes colágenos dérmicos, pequenos vasos na derme superficial com fibrina na parede, alguns ocluídos por trombos, infiltração inflamatória de polimorfonucleares e ausência de leucocitoclasia. Reforça-se a importância do diagnóstico precoce e de maior discussão sobre as opções terapêuticas.
\end{abstract}

Palavras-chave: Vasculite livedoide; Vasos sanguíneos; Atrofia.

\section{ABSTRACT}

A case of livedoid vasculitis is reported in a 41-year-old female patient with painful ulcers in the lower limbs with favorable outcome. A histological study revealed thickening of dermal collagen bundles, which are small vessels in the superficial dermis with fibrin on the walls, some occluded by thrombi, inflammatory infiltrations of polymorphonuclear cells and absence of leukocytoclasia. The importance of early diagnosis, as well as greater discussion about therapeutic options are reinforced.

Keywords: Vasculitis; Blood vessels; Atrophy.

\section{INTRODUÇÃO}

A vasculite livedoide (VL) é rara condição decorrente de alterações nos vasos sanguíneos, que sofrem espessamento, fibrose focal e degeneração de camadas vasculares. Acomete 1:100.000 norte-americanos por ano, principalmente entre $15 \mathrm{a}$ 50 anos. O sexo feminino é mais acometido (2,4-3:1) (CRIADO et al, 2011). Pode ser subdiagnosticada ou confundida com outras vasculites, acarretando maior morbidade e sequelas. $O$ tratamento tem sido objeto de grandes discussões. Entre as opções sugeridas estão heparina de baixo peso molecular, vitamina $\mathrm{K}$, pentoxifilina, varfarina, colchicina, metotrexato, metilprednisolona, ciclosporina ou oxigenioterapia hiperbárica (ALMEIDA et al, 2009). Ademais, há dificuldade em estabelecer-se o diagnóstico correto e o tratamento precoce, pois há muitos diagnósticos diferenciais e falta de consenso terapêutico. Deste modo o presente estudo mostra um relato de caso no 
qual os dados foram coletados durante atividades práticas conforme trâmites preconizados pelo comitê de ética em pesquisa da FAG.

\section{RELATO DO CASO}

Paciente feminina, 41 anos, queixava-se de "feridas e ardência nas pernas" há 3 meses. Realizou vários tratamentos com diferentes especialistas (generalista, médico vascular e ortopedista), sem sucesso. $\mathrm{O}$ angiologista solicitou ecodoppler, que revelou suave refluxo das veias safenas e ausência de sinais de trombose. Apresentava, em dorso dos pés, máculas eritêmato-hipercrômicas de cicatrização recente e lesões úlcero-crostosas, dolorosas, estendendo-se também às regiões perimaleolares, além de algumas lesões bolhosas flácidas (Figuras 1A e 1B). Negava episódios semelhantes na família, e não referia antecedentes mórbidos familiares e pessoais relevantes. Amamentava filho de 3 anos. Fazia uso de losartana e foi-lhe prescrito, por outros médicos, em função das lesões: furosemida, aminaftona, AAS, meloxican e omeprazol e associação de ginkgo biloba com castanha da índia e rutina. Aventou-se a hipótese de vasculite cutânea e foi prescrito compressas com permanganato de potássio, prednisona oral $5 \mathrm{mg}$ 12/12 horas e rifamicina spray (sinais de impetiginização).

Figura 1: Dorso do pé esquerdo do paciente

A

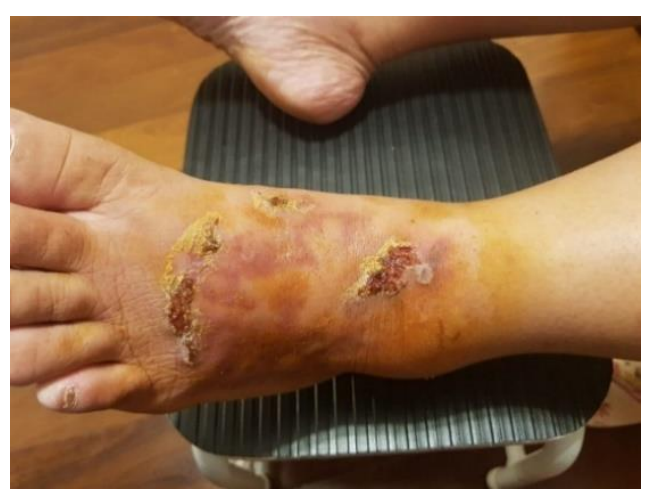

B

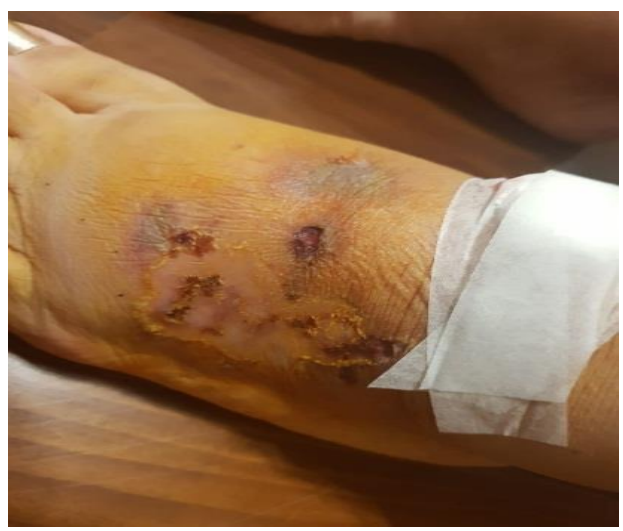

Fonte: prontuário do paciente

Após 17 dias, foi realizada a biópsia. Embora com início de cicatrização das lesões maiores, a paciente apresentava-se ainda com lesões bolhosas e lesões erosivas e dolorosas, além de lesões numulares eritêmato-purpúricas em dorso de pés. Levantou-se então as possibilidades de VL e eritema polimorfo, pelas lesões 
semelhantes às lesões "em alvo". Todas as medicações em uso foram suspensas, exceto losartana, furosemida e omeprazol e o restante da conduta, mantido.

A histologia revelou espessamento de feixes de colágeno dérmicos, pequenos vasos da derme superficial com fibrina na parede, alguns ocluídos por trombos, infiltrado inflamatório de polimorfonucleares e ausência de leucocitoclasia, concluindo por vasculite fibrinóide de pequenos vasos compatível com VL em fase inicial. 37 dias após a biópsia, a paciente retornou com quadro estável. A prednisona foi interrompida e iniciada pentoxifilina $400 \mathrm{mg}$ ao dia e AAS $325 \mathrm{mg}, 2$ vezes ao dia. Por causa da interação com o AAS, solicitou-se a substituição da losartana, que o foi pelo propranolol.

Quinze dias após, as lesões começaram a cicatrizar (figuras 2A e B), embora novas lesões ainda surgissem e a dor retornasse intensa. Por essa razão, foi dobrada a dose de pentoxifilina, manteve-se o AAS e acrescentou-se tramadol $50 \mathrm{mg}$, até de $8 / 8$ horas para a dor.

Figura 2: Dorso do pé esquerdo do paciente

A

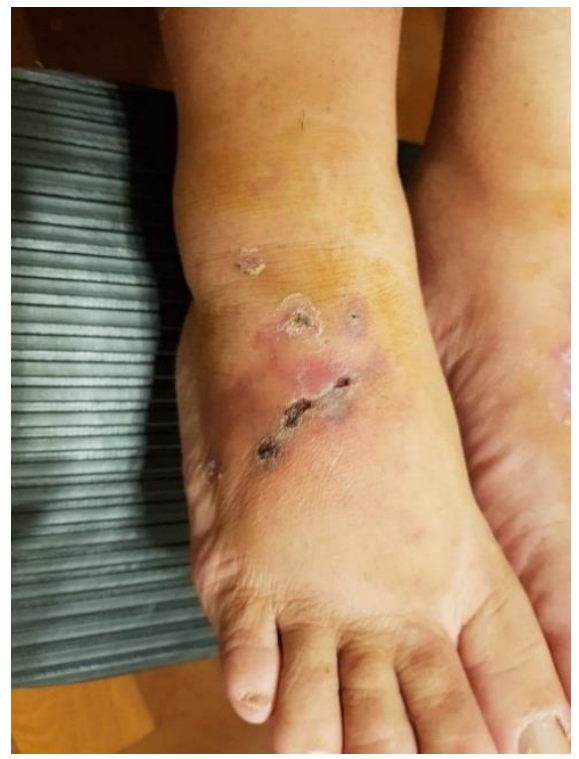

B

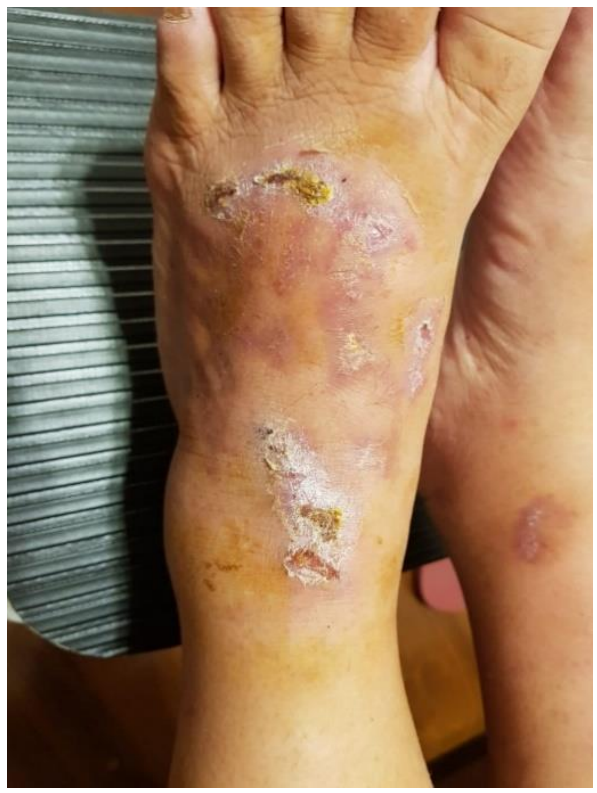

Fonte: prontuário do paciente

Cerca de 40 dias após início da pentoxifilina e do AAS, as lesões haviam diminuído em número e apresentavam-se em processo de cicatrização, embora ainda surgissem novas lesões. Manteve-se a dose da pentoxifilina e o AAS foi reduzido para uma vez ao dia. 10 dias após a consulta anterior, a paciente não mostrava mais lesões ativas, referiu completa cessação da dor e apresentou exames bioquímicos sem 
alterações (anticorpos antifosfolipídeos, hemograma, coagulograma, uréia, creatinina e enzimas hepáticas). Embora solicitado a interrupção, a paciente seguiu tomando a prednisona, $5 \mathrm{mg}$ a cada 12 horas. Imediatamente reduziu-se a prednisona para $5 \mathrm{mg}$ ao dia, prescrito albendazol $400 \mathrm{mg}$ por 3 dias e suspenso o AAS e o tramadol, enquanto a pentoxifilina foi mantida em $800 \mathrm{mg} / \mathrm{dia}$ e o omeprazol em $20 \mathrm{mg} / \mathrm{dia}$. Aos 72 dias após o início da pentoxifilina e 126 dias após a primeira consulta, as lesões permaneciam completamente cicatrizadas e a paciente sem queixas, apenas com hipercromia pós inflamatória em dorso dos pés (figuras 3A e B). A medicação foi, então, descontinuada. Um ano após, a paciente permanecia assintomática e sem tratamento.

Figura 3. Dorso de ambos os pés do paciente

A

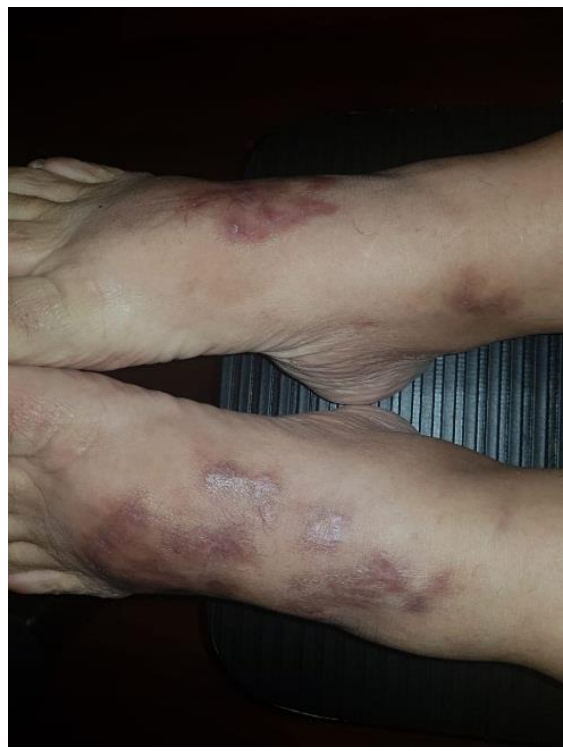

B

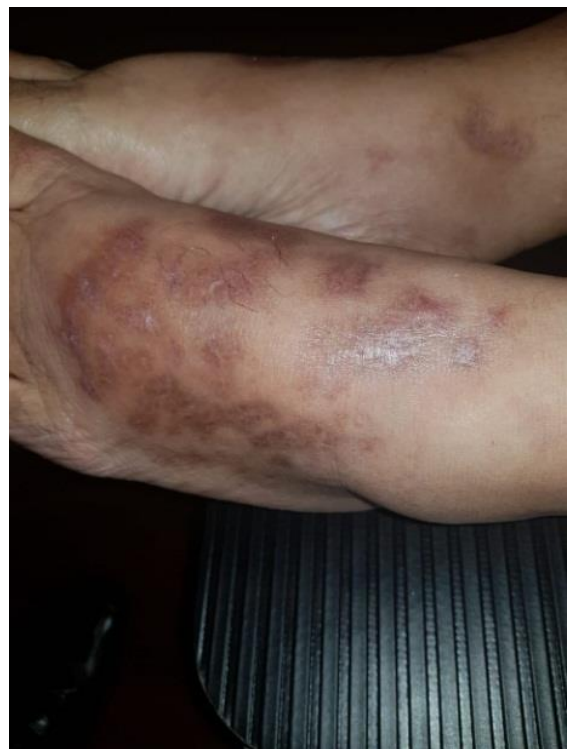

Fonte: prontuário do paciente.

\section{CONCLUSÃO}

A VL, descrita pela primeira vez em 1929 por Milian e denominada atrofia branca, caracteriza-se por envolvimento cutâneo segmentar ou em placas, com resolução em alguns anos ou de caráter crônico. Tipicamente, há deposição de fibrina nos vasos com formação de trombo em seu interior, bem como inflamação com predomínio de neutrófilos na fase inicial e, posteriormente, de linfócitos (ZANINI, WULKAN, BERTINO, ITO, 2003). Vasculites são processos inflamatórios localizados nas paredes dos vasos sanguíneos de calibres variados, podendo também acometer 
o lúmen, provocando isquemia dos tecidos adjacentes. Sua patogênese não é totalmente conhecida. Alteração da resposta imune é uma das explicações mais plausíveis (BARROS, BARROS, 1998).

Estudo com 13 pacientes do sexo feminino e 3 pacientes do sexo masculino com média de 48,3 anos (todos diagnosticados com VL) demonstrou que antiagregantes plaquetários não são tão eficazes no tratamento da doença e que dificilmente irão auxiliar na remissão. Além disso, o tratamento com heparina de baixo peso molecular, vitamina $\mathrm{K}$ e pentoxifilina podem ser eficazes, bem como o uso da varfarina (FRANCÈS, BARETE, 2004).

Uma medida da evolução positiva é a melhora da dor, que é de natureza isquêmica. Os corticoides tópicos e sistêmicos seriam de pouca eficácia e o tratamento, dada a escassez de estudos e conclusões, basear-se-ia na melhor resposta a um dos medicamentos já utilizados com sucesso e por isso recomendados (CRIADO et al, 2011). Em contraste, no presente caso, a evolução, além de favorável, deu-se com a resolução num tempo relativamente curto e até 1 ano após não havia recidivado. É possível que o corticoide sistêmico e o AAS tenham exercido algum efeito, a não ser que toda melhora possa ser creditada à pentoxifilina e/ou a outros fatores não ponderáveis.

\section{REFERÊNCIAS}

ALMEIDA, L. A.; MOTA, L. M. H.; KIRCHENHEIM, R. A. V.; CARNEIRO, J. N. et al. Vasculite Livedóide. Acta Reumatológica Portuguesa, v. 34, n. 3, p. 557, 2009.

BARROS, M. T.; BARROS, R. T. Vasculites: classificação, patogênese e tratamento. Revista Brasileira de Alergia e Imunopatologia, v. 21, n. 4, p. 128-138, 1998.

CRIADO, P. R.; RIVITTI, E. A.; SOTTO, M. N.; VALENTE, N. Y. S. et al. Vasculite livedoide: uma doença cutânea intrigante. Anais Brasileiros de Dermatologia, v. 86, n. 5. P. 961-977, 2011.

FRANCÈS, C.; BARETE, S. Difficult management of livedoide vasculopathy. Archives of Dermatology, v. 140, n. 8, p. 1011, 2004.

ZANINI, M.; WULKAN, C.; BERTINO, D.; ITO, L. Livedoid vasculopathy or vasculitis?. Anais Brasileiros de Dermatologia, v. 78, n. 6, p. 755-757, 2003. 